Hucknall, and Arnold Health Centre. We are particularly grateful to the patients who took part in the study.

Contributors: See bmj.com

Funding: Department of Health.

Competing interests: None declared.

Felson DT, Naimark A, Anderson JJ, Kazis L, Castelli W, Meenan RF. The prevalence of knee osteoarthritis in the elderly: the Framingham prevalence of knee osteoarthritis in the elderty:

2 Badley EM, Tennant A. Disablement associated with rheumatic disorder in a British population: problems with activities of daily living and level of support. BrJ Rheumatol 1993;32:601-8.

3 Fisher NM, Prendergast DR, Gresham GE, Calkins E. Muscle rehabilitation: its effect on muscular and functional performance of patients with knee osteoarthritis. Arch Phys Med Rehabil 1991;72:367-74.

Deyle GD, Henderson NE, Matekel MP, Ryder MG, Garber MB, Allison SC. Effectiveness of manual physical therapy and exercise in osteoarthritis of the knee. A randomized, controlled trial. Ann Intern Med 2000;132:173-81.

5 O'Reilly SC, Muir KR, Doherty M. Screening for knee pain in osteoarthritis: which question? Ann Rheum Dis 1996;55:931-3.

6 Bellamy N, Buchanan WW, Goldsmith CH, Campbell J. Validation study of WOMAC: a health status instrument for measuring clinicallyimportant patient-relevant outcomes following total hip or knee arthroplasty in osteoarthritis. J Ortho Rheumatol 1988;1:95-108.
7 Brazier JE, Harper R, Jones NM, O'Cathain A, Thomas KJ, Usherwood T, et al. Validating the SF-36 health survey questionnaire: new outcome measure for primary care. BMJ 1992;305:160-5.

8 Zigmond AS, Snaith RP. The hospital anxiety and depression scale. Acta Psychiatr Scand 1983;67:361-70.

9 Tornvall G. Assessment of physical capabilities with special reference to the evaluation of maximum voluntary isometric muscle strength. Acto Physiol Scand 1963;58(suppl 201):1-102.

10 Altman RD, Hochberg MC, Murphy WA, Wolfe F. Atlas of individual radiographic features in osteoarthritis. Osteoarthritis Cart 1995;3(suppl A):3-70.

11 Altman DG. Confidence intervals for the number needed to treat. $B M$ J 1998;317:1309-19.

12 Cook RJ, Sackett DL. The number needed to treat: a clinically useful measure of treatment effect. BMJ 1995;310:452-4.

13 Van Barr ME, Dekker J, Oostendorp RA, Bijl D, Voorn TB, Lemmens JA. The effectiveness of exercise therapy in patients with osteoarthritis of hip or knee: a randomised clinical trial. J Rheumatol 1998;25:2432-9.

14 Van Baar ME, Dekker J, Oostendorp RAB, Bijl D, Voom TB, Bijlsma JW, et al. Effectiveness of exercise in patients with osteoarthritis of hip or knee: nine months' follow up. Ann Rheum Dis 2001;60:1123-30.

15 Ettinger WH, Burns R, Messier SP, Applegate W, Rejeski WR, Morgan T et al. A randomized trial comparing aerobic exercise and resistance exercise with a health education program in older adults with knee osteoarthritis. JAMA 1997;277:25-31.

(Accepted 20 June 2002)

\title{
The SCOFF questionnaire and clinical interview for eating disorders in general practice: comparative study
}

\author{
Amy J Luck, John F Morgan, Fiona Reid, Aileen O'Brien, Joan Brunton, Clare Price, Lin Perry,
} J Hubert Lacey

Standards 2 and 3 of the national service framework for mental health outline the need to improve health care for patients with anorexia nervosa and bulimia nervosa. Healthcare workers in primary care are at the forefront of screening and managing these disorders. Assessment tools available to primary healthcare professionals can take a long time to administer and may need to be interpreted by specialists ${ }^{2}$; this may limit improvements in care. A screening tool was developed, but only to facilitate epidemiological research. ${ }^{3}$

The SCOFF questionnaire is a brief and memorable tool designed to detect eating disorders and aid treatment (see figure). It showed excellent validity in a clinical population and reliability in a student population. ${ }^{45}$ We assessed the SCOFF questionnaire in primary care.

\section{Participants, methods, and results}

We invited sequential women attenders (aged 18-50) at two general practices in southwest London to participate. We gave participants information sheets that described the study. Women who verbally consented to participate were asked the SCOFF questions in a separate room; this took about two minutes. A researcher blind to the woman's score on the SCOFF questionnaire conducted a clinical diagnostic interview lasting 10-15 minutes, based on criteria from the Diagnostic and Statistical Manual of Mental Disorders (fourth edition). Women identified by the interview as having an eating disorder were invited to discuss this and were offered the contact number for the Eating Disorders Association. The local research and ethics committee approved the study.
Of the 341 women who agreed to take participate, one (who had a body mass index of 17 (weight $(\mathrm{kg})$ ) height $\left.(\mathrm{m})^{2}\right)$ ) had anorexia nervosa, three had bulimia nervosa, and nine had an "eating disorder not otherwise specified." A receiver operating curve set the optimal threshold for the questionnaire at two or more positive answers to the five questions. With this cut off, the SCOFF questionnaire detected all four cases of anorexia nervosa and bulimia nervosa and seven of nine cases of eating disorders not otherwise specified (figure). The questionnaire had a sensitivity of $84.6 \%$ (95\% confidence interval $54.6 \%$ to $98.1 \%$ ). In the 328 women confirmed not to have an eating disorder, the questionnaire indicated 34 false positives. It had a specificity of $89.6 \%$ ( $86.3 \%$ to $92.9 \%)$, positive predictive value of $24.4 \%(12.9 \%$ to $39.5 \%)$, and negative predictive value of $99.3 \%(97.6 \%$ to $99.9 \%)$.

\section{Comments}

The SCOFF questionnaire detected all cases of anorexia and bulimia nervosa. It is an efficient screening tool for eating disorders.

Two missed cases of eating disorders not otherwise specified reflect the reality of clinical situations, in which denial or non-disclosure by patients may occur. One of the patients in whom the diagnosis was missed later disclosed disordered eating behaviour. It may be more difficult and perhaps less pertinent to detect patients who do not meet full criteria for anorexia nervosa or bulimia nervosa.

The positive predictive value of the questionnaire is low because of the low prevalence of eating disorders in this sample, which was consistent with the Western
Department of

Psychiatry,

St George's

Hospital Medical

School, University

of London, London

SW17 0RE

Amy J Luck

research fellow

John F Morgan

senior lecturer in

liaison psychiatry

Aileen O'Brien

lecturer in community

psychiatry

Joan Brunton

lecturer in psychiatry

Clare Price

clinical research fellow

in psychiatry

$\mathrm{J}$ Hubert Lacey

chairman

Department of

Public Health

Sciences,

St George's

Hospital Medical

School

Fiona Reid

lecturer in medical

statistics

Faculty of Health

and Social Care

Sciences,

St George's

Hospital Medical

School

Lin Perry

research fellow

Correspondence to:

J F Morgan

BMJ 2002;325:755-6 


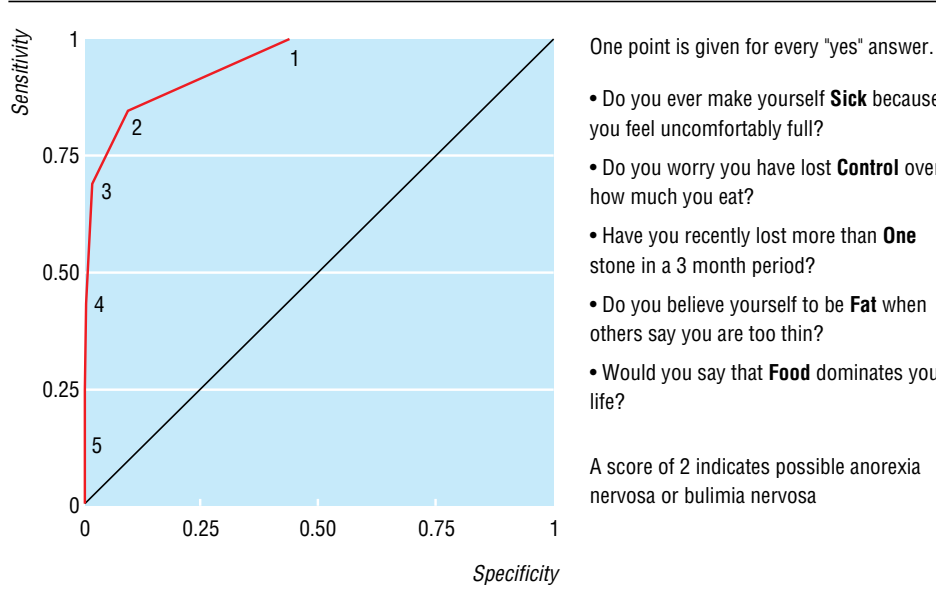

Receiver operating curve showing the effect of cut-off points (1 to 5 ) for the SCOFF questionnaire to detect cases and non-cases of eating disorders. 1 to $5=$ minimum number of positive responses to questionnaire

population as a whole. Overinclusion is acceptable for screening instruments designed for disorders with high mortality rates, particularly as the questionnaire is short and easy to administer. Positive results should be followed by further questioning rather than by automatic referral.

The SCOFF questionnaire is efficient at detecting cases of eating disorders in adult women in primary care. We recommend its use by healthcare professionals in primary care. Future work will assess the validity of the questionnaire in other populations, such as adolescents, in whom the prevalence may be higher.

Study to be attributed to the Department of Psychiatry at St George's Hospital Medical School, University of London, London. We thank K Kennett for her help with data collection. We also thank Wandle Valley Surgery and Brocklebank Group Practice, particularly T Coffey, who provided study patients. We thank the volunteers for their kind participation.

Contributors: All authors contributed to the conception and design of the study. $\mathrm{AL}, \mathrm{AO} \mathrm{B}^{\mathrm{B}}, \mathrm{JB}$, and $\mathrm{CP}$ were responsible for the collection and management of data. AL, FR, and JM analysed and interpreted data. AL wrote the paper and all other authors oversaw the writing and edited the paper. JM and HL will act as guarantors.

Funding: None.

Competing interests: None declared.

1 Department of Health. A national service framework for mental health: modern standards and service models. London: Stationery Office, 1999.

2 Garner DM, Olmstead MA, Polivy J. Development and validation of a multidimensional eating disorder inventory for anorexia nervosa and bulimia. Int J Eat Disord 1983;2:15-34.
3 Beglin SJ, Fairburn CG. Evaluation of a new instrument for the detection of eating disorders in community samples. Psychiatry Res 1992;44:191201.

4 Morgan JF, Reid F, Lacey JH. The SCOFF questionnaire: assessment of a new screening tool for eating disorders. BMJ 1999;319:1467-8.

5 Perry L, Morgan J, Reid F, O'Brien A, Brunton J, Luck A, et al. Oral versus written administration of the SCOFF. Int J Eating Disorders (in press). (Accepted 28 February 2002)

\section{Correction}

Resource implications and health benefits of primary prevention strategies for cardiovascular disease in people aged 30 to 74 . mathematical modelling study

The authors of this primary care paper, Tom Marshall and Andrew Rouse, have alerted us to some errors in the costings given for the follow up of patients (27 July, pp 1979). They have confirmed that despite this the conclusions of the article remain the same.

Firstly, in table 2 in the web version (bmj.com), the costs should read, downwards: £3567; £18 290; £32 628; £3567; $£ 6758$; £24 489; £36 233; £14 983; £25 975; £46 270; and $£ 34950$. The heading for that column should read: "Cost per event prevented."

Secondly, the first three paragraphs of the results section should read as below.

Technical efficiency: maximising benefits within total resources

For any given allocation of resources to primary prevention of cardiovascular disease more cardiovascular events can be prevented under RM strategies than the equivalent JBR strategies. A primary care team can prevent 5.7 events for $£ 40934$ under strategy RM-2 or 5.7 events for $£ 28090$ under RM-3. The most efficient strategy for a primary care team with a budget of $£ 40934$ is therefore RM-3. A primary care team can prevent 7.6 events for $£ 116233$ under strategy RM-1 or 7.6 events for $£ 86696$ under RM-2. The most efficient strategy for a primary care team with a budget of $£ 116233$ is therefore RM-2. For a primary care team with a budget of over $£ 116233$ the most efficient strategy is RM-1.

Maximising efficiency within available clinical staff time

[After second sentence] At one clinic a month there is not sufficient clinical time to assess all eligible adults. JBR strategies therefore cannot be implemented. Strategy RM-3 can prevent 4.0 cardiovascular events at a cost of £3567 per event prevented. RM-2 can prevent 1.1 more events at an incremental cost of $£ 18290$ per event prevented. RM-1 can prevent 2.5 more events than RM-2 at an incremental cost of $£ 32628$ per event prevented.

Compared with one clinic a month, allocating two clinics a month to RM-3 can prevent 1.6 more events at a cost of $£ 6758$ per event prevented. Allocating two clinics a month to RM-2 prevents a further 1.7 events at an incremental cost of $£ 24489$ per event prevented. Two clinics a month following strategy RM-1 prevents a further 3.5 cardiovascular events at an incremental cost of £36 233 per event prevented.

\section{Submitting articles to the $B M J$}

We are now inviting all authors who want to submit a paper to the $B M J$ to do so via the web (http://submit.bmj.com).

Benchpress is a website where authors deposit their manuscripts and editors go to read them and record their decisions. Reviewers' details are also held on the system, and when asked to review a paper reviewers will be invited to access the site to see the relevant paper. The system is secure, protected by passwords, so that authors see only their own papers and reviewers see only those they are meant to.

Anyone with an internet connection and a web browser can use the system.
The system provides all our guidance and forms and allows authors to suggest reviewers for their paper. Authors get an immediate acknowledgement that their submission has been received, and they can watch the progress of their manuscript. The record of their submission, including editors' and reviewers reports, remains on the system for future reference.

The system itself offers extensive help, and the BMJ's editorial office will help authors and reviewers if they get stuck.

Benchpress is accessed via http://submit.bmj.com or via a link from bmj.com 